\title{
Social desirability bias in relation to academic cheating behaviors of nursing students
}

\author{
Amanda Rene Winrow *, Amy Reitmaier-Koehler, Brian Paul Winrow \\ Winona State University, Winona, United States
}

Received: April 27, 2015

Accepted: May 22, 2015

Online Published: June 15, 2015

DOI: $10.5430 /$ jnep.v5n8p121

URL: http://dx.doi.org/10.5430/jnep.v5n8p121

\begin{abstract}
The purpose of this study was to explore the relationship between academic cheating and a series of academic and demographic characteristics, as well as the relationship between the various characteristics and social desirability bias. The population for the study was comprised of 626 nursing students (pre-nursing, baccalaureate students formally admitted into the program, and graduate students) attending a regional comprehensive university located in the Midwest. The results of the study revealed that $53.8 \%$ of undergraduate students and $36.5 \%$ of graduate students self-reported having engaged in at least one of the 16 forms of academic cheating during the previous semester, primarily in acts classified as plagiarism. The current study further explored misconduct among students seeking a BSN and found that $35.2 \%$ of students participated in at least one act of professional misconduct in the clinical setting. There were statistically significant differences between the characteristics of age and prevalence of plagiarism-related academic cheating, planned cheating, spontaneous cheating, and professional misconduct, implying that older students cheat less frequently. Likewise, the more credits a student completed the less likely they were to plagiarize or engage in spontaneous cheating. Additionally, older students and students having completed higher number of credits received higher scores on the social desirability scale, implying they had a higher tendency to display social desirability bias.
\end{abstract}

Key Words: Academic cheating, Nursing, Social desirability bias, Plagiarism, Clinical misconduct

\section{INTRODUCTION}

Admission into many nursing programs across the United States remains highly competitive, with low acceptance rates. While universities utilize different formulas when evaluating applicants for admission into their respective programs, one uniform factor is the utilization of the grade point average as a screening tool to help identify students likely to excel in the academically challenging program. Due to the highly competitive admission policies and reliance on grade point averages, students might be tempted to engage in academic misconduct to gain a perceived competitive advantage. The motive to cheat academically is supported by existing research; these studies indicate that one of the primary reasons students partake in academic cheating is to advance their current station in life. ${ }^{[1,2]}$ However, students' engagement in academic cheating skews the screening process, rewarding students unable to achieve the criteria based upon their own academic merits.

Implementation of safeguards to resist misconduct proves warranted, as previous studies have elucidated that up to $87 \%$ of students have participated in behaviors classified as academic cheating. ${ }^{[3]}$ Even as extant research indicates that business students cheat the most frequently ${ }^{[3]}$ Kruger $^{[4]}$ found that as many as $64.7 \%$ of nursing students admitted to cheating in the classroom setting, with $54 \%$ reporting having engaged in academic misconduct in the clinical setting. However, while previous research has investigated academic cheating in nursing programs, the literature has failed to

*Correspondence: Amanda Rene Winrow; Email: awinrow@winona.edu; Address: Winona State University, Winona, United States. 
explore the impact of social desirability bias, essential to assess when relying on self-reported instances of academic cheating.

Social desirability bias is defined as the propensity of a respondent to answer questions in such a capacity as to deny socially undesirable behaviors while admitting to socially desirable ones. ${ }^{[5]}$ The lack of control for social desirability in nursing studies is not surprising as only one percent of studies across all disciplines account for the prospect of social desirability bias, ${ }^{[6]}$ even though $90 \%$ of the studies that focus on academic cheating rely on self-report data. ${ }^{[7]}$ Thus, the primary purpose of this study centers on whether the presence of social desirability bias varies with respect to the enumerated academic and demographic characteristics. Since social desirability has previously been found to bias the results of self-reported cheating, ${ }^{[7]}$ this article advances the existing literature by assessing the relationship between selfreported levels of academic cheating and social desirability bias. Moreover, this study explores the relationships between the enumerated characteristics and social desirability bias. The four research questions for this study are as follows:

- Research Question 1: Does the frequency of academic misconduct vary with respect to the demographic and academic characteristics of the students?

- Research Question 2: Does social desirability bias vary with respect to the demographic and academic characteristics of the students?

- Research Question 3: Does the frequency of academic misconduct in the classroom vary with respect to misconduct in the clinical setting?

- Research Question 4: Does the frequency of academic misconduct vary with respect to familiarity with the academic code?

\subsection{Literature review}

Universities continue to struggle to contain academic cheating, a serious problem. According to a systematic review conducted by Whitley ${ }^{[8]}$ of 107 articles published on academic cheating in post-secondary institutions, the median percentage of students who had engaged in academic cheating was $70.4 \%$, with a range from $9 \%$ to $95 \%$. Likewise, Kruger ${ }^{[4]}$ found that $64.7 \%$ of nursing students self-reported as having engaged in at least one act of academic misconduct. The adverse consequences of academic misconduct are not confined to the classroom ${ }^{[9]}$ and can negatively impact patients by credentialing students who lack the professional skills and competency necessary to provide skilled care. ${ }^{[10]}$ In addition to producing nurses who lack the fundamental knowledge and skills to meet the requisite standard of care, previous research found a relationship between classroom cheating and misconduct in the clinical setting. ${ }^{[11]}$ Compounding the importance of identifying and preventing academic cheating through education and safeguards are ample studies that find that students who academically cheat are more likely to engage in workplace misconduct. ${ }^{[12]}$

Over the past decade much research has been published concentrating on the prevalence of academic cheating. The primary forms of academic cheating include behaviors such as plagiarism ${ }^{[13,14]}$ cheating on exams ${ }^{[15,16]}$ improperly working together on assignments, ${ }^{[17]}$ allowing others to unethically extract information from their exams or assignments, ${ }^{[17-19]}$ and misconduct in the clinical setting, such as violating patient confidentiality protections and improperly recording procedures that were not performed. ${ }^{[4,20]}$ Additionally, prior research focused on distinguishing between premeditated cheating and spontaneous cheating. ${ }^{[21,22]}$ While much of the literature focused on distinct forms of academic cheating, four common themes emerged: intentional acts of cheating versus spontaneous cheating on exams, plagiarism, improper use of resources, and professional misconduct in the clinical setting. Each stream of literature is briefly addressed in the following subsections.

\subsubsection{Premeditated versus spontaneous cheating}

Extant literature distinguished between planned and spontaneous cheating, with the majority of students believing that most instances of cheating were spontaneous, ${ }^{[21]}$ also referred to as panic cheating. A common example of panic cheating includes looking at a classmate's exam and copying the answer. ${ }^{[23]}$ In contrast, premeditated cheating occurs when the student enters the exams with the intent to cheat, such as bringing unpermitted resources to the classroom with the purpose of using the resource on the exam. According to Hard, Conway, and Moran ${ }^{[22]}$ up to one third of students engaged in premeditated acts of cheating.

\subsubsection{Plagiarism}

In addition to the gap between planned and spontaneous cheating, much literature has explored the construct of plagiarism. In 1998, Whitley's ${ }^{[8]}$ review of 107 studies published on academic cheating found a mean of $47 \%$ of students who had engaged in plagiarism. Even as nearly half of the students engaged in acts construed as plagiarism, advancements in technology have induced increased plagiarism. Indeed, according to Etter, Cramer, and Finn ${ }^{[24]}$ plagiarism has increased four-fold over the past five years. Moreover, the Center for Academic Integrity found that the number of students indulging in plagiarism from online sites increased $400 \%$ from 2000-2005 ${ }^{[25]}$ consistent with a study published in The Chronicle of Higher Education in 2002 that found $25 \%$ of post-secondary students self-reported as having plagiarized

ISSN 1925-4040 E-ISSN 1925-4059 
from online sources by cutting and pasting, without attributing credit. ${ }^{[26]}$ Furthermore, extant research also indicated that the prevalence of plagiarism transcended geographical boundaries and was also subject to cultural differences. For example, one university in China classified plagiarism as copying over 1000 words without attributing credit to the original author, the punishment being a serious warning. ${ }^{[27]}$

\subsubsection{Improper use of resources}

Another stream of literature focused on the improper use of resources. The existing literature reflected a variety of methods through which nursing students improperly use resources, such as seeking assistance on homework from practitioners and then submitting the assignment as their own work ${ }^{[28]}$ and creating false excuses to delay taking an exam or other assessment measures. ${ }^{[29]}$ Other improper uses the literature elucidated include purchasing papers, improperly obtaining and/or distributing exams, using unauthorized resources on an assignment, and falsifying data. ${ }^{[30]}$ Alarmingly, to facilitate improper uses of resources, several websites have emerged, dedicated to provide students with a systematic manual on how to cheat successfully. ${ }^{[31]}$

\subsubsection{Professional misconduct in the clinical setting}

Clinical misconduct is the remaining central stream of literature relating to misconduct in the nursing field. ${ }^{[4,20]}$ Forms of clinical misconduct include improperly disclosing information about a patient in violation of privacy laws; damaging or stealing a patients personal effects; and falsifying medical records, e.g., erroneously stating an assessment was conducted. ${ }^{[20]}$ Several studies found a correlation between prevalence of academic cheating and clinical misconduct. ${ }^{[4,11]}$

\section{Methodology}

The population for this study included all students who declared a nursing major at a mid-sized public university in the Upper Midwest (herein referred to as University X) during the Spring 2014 semester. The Department of Nursing at University X offers a bachelor's degree, MSN, post-graduate certificates, and the DNP. According to the 2014 spring semester institutional reports, the Department of Nursing had 1,340 students. For the purposes of this study, students were classified as pre-nursing (not yet admitted into the baccalaureate program), Terms 1, 2, 3, and 4 within the nursing program (representing admitted students and their respective cohorts, with term 4 comprised of students in their final semester of the program), masters, graduate certificate, and DNP. Additionally, University X has a modified honor code that provides general definitions of acts considered academic cheating, as well as the governing procedural process initiated when students are accused of cheating. University $\mathrm{X}$ permits the use of proctors during exams. The Department of

Published by Sciedu Press
Nursing, however, does not have a department specific honor code.

\subsection{Response rate}

A census was employed to ensure all members of the population had an opportunity to complete the survey. The population was obtained from a list maintained by University X. The list contained the names of the students and their email addresses. The survey was electronically administered to all 1,340 students via their official university email account. A total of 626 surveys were completed for a response rate of $46.7 \%$.

\subsection{Survey instrumentation}

The data were collected using the following scales: (a) a modified version of the Survey of Student Academic Misconduct as developed by Hard, Conway, and Moran ${ }^{[22]}$ to measure the level of self-reported academic cheating; (b) the clinical misconduct section developed by McCrink ${ }^{[20]}$ to measure student misconduct in the clinical setting; (c) the $M$-C1(10) Social Desirability Scale, as developed by Strahan and Gerbasi, ${ }^{[32]}$ to guard against social desirability bias.

Student academic cheating and professional misconduct. To measure the dependent variable, the prevalence of undergraduate academic cheating by nursing students, the statements contained on Hard et al.'s ${ }^{[22]}$ Survey of Student Academic Misconduct were adopted for the purposes of this study. The Survey of Student Academic Misconduct scale was selected as it entailed statements that correlated with the frequent forms of academic cheating identified in the literature. Additionally, nine questions were adopted from the McCrink ${ }^{[20]}$ study that focused on student misconduct in the clinical setting.

M-C1(10) social desirability scale. To measure the mediating variable, social desirability bias, the Strahan and Gerbasi M-C1(10) Social Desirability Scale was used. This survey was designed to control for social desirability bias and is frequently used when conducting self-report surveys. The 10 question M-C1(10) is a short form version of the 33 question Marlowe-Crowe Social Desirability Scale. ${ }^{[32]}$ The scale was originally validated by Strahan and Gerbasi ${ }^{[32]}$ that utilized a study involving 500 undergraduate students. The M-C1(10) Scale was found to be strongly correlated with the longer Marlowe-Crowne scale, with an alpha score greater than 0.80 .

\section{Results}

The results are presented in three sections. The first section describes the characteristics of the participants. The second section presents a descriptive analysis of the items used to 
measure misconduct. The third section presents the evidence to address the research questions.

\subsection{Demographic and academic characteristics of the participants}

A total of $\mathrm{N}=657$ participants responded to the survey; however, $4.6 \%(n=31)$ did not complete the 25 items concerning misconduct, and so they were excluded from the analysis, with a valid response rate of $46.7 \%$. Table 1 and Table 2 summarize the demographic and academic characteristics of $\mathrm{N}=626$ participants who completed the items concerning misconduct.

The sample was dominated by female participants $(n=569$,
$90.7 \%)$. Their ages ranged from 18 to 65 years, but the majority $(n=403,64.1 \%)$ were 18 to 21 years old. The most frequent educational level of their parents $(n=229,36.5 \%)$ was a Bachelor degree. Most of the students $(n=422,67.3 \%)$ attended the main campus. Approximately one half of the students ( $n=307,49.0 \%)$ were in the Pre-nursing or Nursing Term 1 program; the others were in Nursing Term 2, 3, or 4 $(n=244,38.9 \%)$ or pursuing postgraduate degrees $(n=60$, $11.7 \%)$. About two thirds of the students $(n=419,66.8 \%)$ had completed fewer than 90 credits. The majority $(\mathrm{n}=$ $67.5 \%$ ) had a cumulative GPA between 3.50 and 4.00. Most participants $(n=528,84.2 \%)$ reported that they were very familiar, familiar, or somewhat familiar with the university honor code.

Table 1. Demographic characteristics of the participants $(\mathrm{N}=626)$

\begin{tabular}{llll}
\hline Characteristic & Category & N & \% \\
\hline \multirow{2}{*}{ Gender } & Male & 57 & $9.1 \%$ \\
& Female & 569 & $90.7 \%$ \\
& $18-19$ & 198 & $31.6 \%$ \\
& $20-21$ & 205 & $32.5 \%$ \\
& $22-23$ & 63 & $10.0 \%$ \\
Age (Years) & $24-25$ & 10 & $1.6 \%$ \\
& $26-35$ & 89 & $14.1 \%$ \\
& $36-45$ & 39 & $6.2 \%$ \\
Highest level of education of parents & $46-55$ & 17 & $2.7 \%$ \\
& S6-65 & 5 & $0.8 \%$ \\
& Never attended college & 95 & $15.2 \%$ \\
& Bachelor Degree & 202 & $32.2 \%$ \\
\end{tabular}

\subsection{Descriptive analysis}

Academic misconduct. Academic misconduct (i.e., cheating in classroom settings) was measured using 16 items with a dichotomous response format (1, Yes or 0 , No). The overall frequency of academic cheating is contained in Table 3 , segmented into (a) pre-nursing (declared major but not admitted into nursing program); (b) terms 1-4 (admitted into program); (c) composite score for students in terms 1-4; (d) total undergraduate cheating; (e) masters program; (f) graduate certificate; (g) DNP; and (h) composite percentage for all graduate students. Overall, the majority of undergraduate students $(53.8 \%)$ admitted to having engaged in at least one act of academic cheating during the preceding semester. Prenursing students $(56.6 \%)$ reported having cheated at least once at a slightly higher rate than undergraduate students who were admitted into the nursing program (51.2\%). In contrast, only $36.5 \%$ of graduate students reported having engaged in academic cheating during the preceding semester. In addition to looking at academic cheating in the classroom, Table 3 also contains self-reported levels of students having engaged in professional misconduct within the clinical setting. Misconduct in the clinical setting was limited to undergraduate students admitted into the nursing program and currently enrolled in terms 2,3 , or 4 , as they were the only terms in which the students were required to have been engaged in the clinical setting during the previous semester. As illustrated in Table 3, 35.2\% of respondents admitted having engaged in at least one act of misconduct in the clinical setting, with term 2 students having the highest rate $(39.7 \%)$. Table 5 contains the distinct actions construed as misconduct within the clinical setting, with the overall percentages of students having reported engaging in said behavior. 
Table 2. Academic characteristics of participants $(\mathrm{N}=626)$

\begin{tabular}{llll}
\hline Characteristic & Category & $N$ & $\%$ \\
\hline \multirow{5}{*}{ Program } & Pre-nursing & 264 & $42.1 \%$ \\
& Nursing Term 1 & 43 & $6.9 \%$ \\
& Nursing Term 2 & 78 & $12.4 \%$ \\
& Nursing Term 3 & 58 & $9.3 \%$ \\
& Nursing Term 4 & 108 & $17.2 \%$ \\
& Master's Degree & 56 & $8.9 \%$ \\
& Graduate Certificate & 4 & $0.6 \%$ \\
& DNP & 14 & $2.2 \%$ \\
& $0-29$ & 145 & $23.1 \%$ \\
Semester credits completed & $30-59$ & 138 & $22.0 \%$ \\
& $60-89$ & 122 & $19.5 \%$ \\
& $\geq 90$ & 161 & $25.7 \%$ \\
& Graduate student & 57 & $9.1 \%$ \\
& $3.75-4.00$ & 252 & $40.2 \%$ \\
Cumulative GPA & $3.50-3.74$ & 170 & $27.1 \%$ \\
& $3.25-3.49$ & 120 & $19.1 \%$ \\
& $3.00-3.24$ & 53 & $8.5 \%$ \\
& $2.75-2.99$ & 16 & $2.6 \%$ \\
& $2.50-2.74$ & 9 & $1.4 \%$ \\
Familiarity with University & $2.25-2.49$ & 3 & $0.5 \%$ \\
honor code & $2.00-2.24$ & 1 & $0.2 \%$ \\
& $\leq 1.99$ & 2 & $0.3 \%$ \\
& Very familiar & 103 & $16.4 \%$ \\
& Familiar & 215 & $34.3 \%$ \\
& Somewhat familiar & 210 & $33.5 \%$ \\
& Somewhat unfamiliar & 33 & $5.3 \%$ \\
& Unfamiliar & 49 & $2.8 \%$ \\
& Very unfamiliar & 17 & $2.7 \%$ \\
\hline
\end{tabular}

While Table 3 provides the overall levels of cheating, the frequencies of the responses are summarized in Table 4, classified into four categories to better understand the forms of cheating: (a) plagiarism; (b) improper use (of paper, materials, or data); (c) planned cheating; and (d) spontaneous cheating. The majority of students $(65.6 \%$ to $99.2 \%)$ did not admit to cheating depending on the item. The most frequent form of cheating was plagiarism, specifically (a) Worked with another student on material to be submitted for academic evaluation when the instructor had not authorized working together $(\mathrm{n}=216,34.4 \%)$; (b) Copied information directly, or in slightly modified form, from either Internet websites or other sources without proper acknowledgement to the original author or source $(\mathrm{n}=167,26.6 \%)$; or (c) Submitted the same work, or substantially the similar work, in more than one course without prior consent of the evaluating instructors $(\mathrm{n}=68,10.8 \%)$; and spontaneous cheating, specifically, Did not plan, but did copy an examination $(n=87$, $13.9 \%$ ). The least frequent form of cheating was improper use of paper, materials, or data, specifically (a) Improperly acquired or distributed examinations $(\mathrm{n}=5,0.8 \%)$ and (b) Bought papers for purposes of turning them in as your own work $(n=5,0.8 \%)$.

Professional misconduct in clinical settings in the previous semester was measured using nine items with a dichotomous response format ( 1 , Yes or $0, \mathrm{No}$ ) for $\mathrm{N}=244$ undergraduate nursing students in terms 2,3 , and 4 . The frequencies of the responses are summarized in Table 5.

The vast majority of participants (77.5\% to $99.6 \%$ ) did not admit to professional misconduct, depending on the item. The most frequent forms of professional misconduct were (a) Discussed clients in public places or with nonmedical personnel ( $\mathrm{n}=55,22.5 \%)$; and (b) Reported or recorded vital signs that were not taken or recalled accurately $(n=31$, $21.7 \%$ ). The least frequent forms of professional misconduct were (a) Recorded medications as given when they were not given and Lost, broke, or damaged clients' belongings and did not report it $(n=1,0.4 \%)$. 
Composite scores for misconduct. The frequencies of "Yes" responses (scoring 1) provided by each participant for the items measuring the five categories of misconduct, specifically (a) plagiarism; (b) improper use; (c) planned cheating; (d) spontaneous cheating; and (e) professional misconduct were composited by summation. The composite scores represented the extent of misconduct in each category reported by each participant. Figure 1 presents the frequency distributions of the composite scores for the five categories of misconduct. The descriptive statistics, including reliability analysis, are presented in Table 6 .

The internal consistency reliability of the five variables was adequate, indicated by the results of the reliability analysis for the dichotomous scores that constituted each variable (Kuder-Richardson 20 coefficient $\geq$.6). The results justified addition of the scores to construct composite variables. Strong positive skewness proved characteristic feature of the frequency distributions of the composite variables. Each frequency distribution had a conspicuous mode corresponding to zero items of misconduct. Zero was median score for each category.

Social desirability bias. The responses to the 10 items in the short form of the Crown-Marlowe Social Desirability Scale were initially coded as True $=1$ and False $=0$. The scores for the five socially undesirable items $(2,5,6,7$, and 10) were reversed to True $=0 ;$ False $=1$. Consequently, a score of 1 meant that that the participant was deliberately trying to portray him/herself positively, by endorsing a socially desirable behavior. The most frequent scores of 1 were for (a) I always try to practice what I preach $(\mathrm{n}=589,93.9 \%)$; (b) I am always willing to admit it when I make a mistake ( $n=476,75.9 \%$ ); (c) I never resent being asked to return a favor $(n=466,74.3 \%)$ and (d) I sometimes try to get even rather than forgive and forget $(n=456,72.7 \%)$. The scores are displayed in Table 7.

The scores for each participant were summated to operationalize the Social Desirability Scale, ranging from 1 to 10, such that the higher the score, the higher the level of social desirability bias. The internal consistency reliability of this scale proved adequate (Kuder-Richardson $20=.609$ ). The frequency distribution histogram in Figure 2 indicates that that Social Desirability Scale appeared visually to approximate normality, reflected by its fit to a bell-shaped curve. The descriptive statistics $(\mathrm{M}=5.76$; $\mathrm{Mdn}=6.00 ; \mathrm{SD}=2.1$; Skewness $=-0.20)$ reflected the central tendency of the scale. A lower score on the Social Desirability Scale $(\leq 5)$ indicated that less than half of the students exhibited a low to moderate propensity for endorsing socially desirable behaviors ( $\mathrm{n}=$ 276, 44.0\%). A higher score on the Social Desirability Scale ( $>$ 5) implied that more than a half of the students exhibited a higher propensity for endorsing socially desirable behaviors $(n=351,56.0 \%)$.

Table 3. Prevalence of cheating among students based upon program level

\begin{tabular}{|c|c|c|c|c|}
\hline \multirow{2}{*}{ Item } & \multicolumn{2}{|l|}{ No } & \multicolumn{2}{|l|}{ Yes } \\
\hline & $N$ & $\%$ & $n$ & $\%$ \\
\hline \multicolumn{5}{|l|}{ Academic Cheating: } \\
\hline Pre-nursing & 115 & $43.4 \%$ & 150 & $56.6 \%$ \\
\hline \multicolumn{5}{|c|}{ Undergraduate Admitted into Nursing Program } \\
\hline • $\quad$ Nursing Term 1 & 18 & $41.9 \%$ & 25 & $58.1 \%$ \\
\hline - $\quad$ Nursing Term 2 & 33 & $42.3 \%$ & 45 & $57.7 \%$ \\
\hline - $\quad$ Nursing Term 3 & 34 & $58.6 \%$ & 24 & $41.4 \%$ \\
\hline - $\quad$ Nursing Term 4 & 55 & $50.9 \%$ & 53 & $49.1 \%$ \\
\hline - $\quad$ Total Admitted into Program & 140 & $48.8 \%$ & 147 & $51.2 \%$ \\
\hline Total Undergraduate Nursing & 255 & $46.2 \%$ & 297 & $53.8 \%$ \\
\hline \multicolumn{5}{|l|}{ Graduate Nursing Program } \\
\hline - $\quad$ Masters & 34 & $60.7 \%$ & 22 & $39.3 \%$ \\
\hline - $\quad$ Graduate Certificate & 3 & $75 \%$ & 1 & $25 \%$ \\
\hline - $\quad D N P$ & 10 & $71.4 \%$ & 4 & $28.6 \%$ \\
\hline - Total Graduate & 47 & $63.5 \%$ & 27 & $36.5 \%$ \\
\hline \multicolumn{5}{|l|}{ Clinical Misconduct } \\
\hline Nursing Term 2 & 47 & $60.3 \%$ & 31 & $39.7 \%$ \\
\hline Nursing Term 3 & 41 & $70.7 \%$ & 17 & $29.3 \%$ \\
\hline Nursing Term 4 & 70 & $64.8 \%$ & 38 & $35.2 \%$ \\
\hline Total Misconduct in Clinical Setting & 158 & $64.8 \%$ & 86 & $35.2 \%$ \\
\hline
\end{tabular}


Table 4. Frequencies of responses to items measuring academic misconduct

\begin{tabular}{|c|c|c|c|c|}
\hline \multirow{2}{*}{ Item } & \multicolumn{2}{|l|}{ No } & \multicolumn{2}{|l|}{ Yes } \\
\hline & $N$ & $\%$ & $n$ & $\%$ \\
\hline \multicolumn{5}{|l|}{ Plagiarism: } \\
\hline $\begin{array}{l}\text { Worked with another student on material to be submitted for academic evaluation when } \\
\text { the instructor had not authorized working together. }\end{array}$ & 411 & $65.6 \%$ & 216 & $34.4 \%$ \\
\hline $\begin{array}{l}\text { Copied information directly, or in slightly modified form, from either Internet websites } \\
\text { or other sources without proper acknowledgement to the original author or source. }\end{array}$ & 460 & $73.4 \%$ & 167 & $26.6 \%$ \\
\hline $\begin{array}{l}\text { Submitted the same work, or substantially the similar work, in more than one course } \\
\text { without prior consent of the evaluating instructor(s). }\end{array}$ & 559 & $89.2 \%$ & 68 & $10.8 \%$ \\
\hline $\begin{array}{l}\text { Realized that during an exam that another student wanted to copy from your paper, and } \\
\text { allowed that student to copy. }\end{array}$ & 571 & $91.1 \%$ & 56 & $8.9 \%$ \\
\hline Prepared work for another student to submit for academic evaluation. & 592 & $94.4 \%$ & 35 & $5.6 \%$ \\
\hline Sold or lent papers so another student could turn them in as his or her own work. & 615 & $98.1 \%$ & 12 & $1.9 \%$ \\
\hline Submitted another’s material as one’s own for academic evaluation. & 616 & $98.2 \%$ & 11 & $1.8 \%$ \\
\hline \multicolumn{5}{|l|}{ Improper use: } \\
\hline $\begin{array}{l}\text { Used unauthorized material or fabricated data in an academic exercise: for example, } \\
\text { falsifying data in a research paper or laboratory activity. }\end{array}$ & 581 & $92.7 \%$ & 46 & $7.3 \%$ \\
\hline Improperly acquired or distributed examinations. & 622 & $99.2 \%$ & 5 & $0.8 \%$ \\
\hline Bought papers for purposes of turning them in as your own work. & 622 & $99.2 \%$ & 5 & $0.8 \%$ \\
\hline \multicolumn{5}{|l|}{ Planned cheating: } \\
\hline Planned and copied during an examination. & 590 & $94.1 \%$ & 37 & $5.9 \%$ \\
\hline $\begin{array}{l}\text { Planned to and then used unauthorized materials during an exam when the instructor has } \\
\text { not approved their use. }\end{array}$ & 602 & $96.0 \%$ & 25 & $4.0 \%$ \\
\hline $\begin{array}{l}\text { Planned to and then allowed another person to copy from your paper during an } \\
\text { examination. }\end{array}$ & 602 & $96.0 \%$ & 25 & $4.0 \%$ \\
\hline \multicolumn{5}{|l|}{ Spontaneous cheating: } \\
\hline Did not plan, but did copy an examination. & 540 & $86.1 \%$ & 87 & $13.9 \%$ \\
\hline Did not plan to, but did use unauthorized materials or devices during an examination. & 598 & $95.4 \%$ & 29 & $4.6 \%$ \\
\hline $\begin{array}{l}\text { Did not plan to, but did allow another person to copy from your paper during an. } \\
\text { examination. }\end{array}$ & 574 & $91.5 \%$ & 53 & $8.5 \%$ \\
\hline
\end{tabular}

Table 5. Frequencies of responses for 9 items measuring professional misconduct

\begin{tabular}{|c|c|c|c|c|}
\hline \multirow{2}{*}{ Item } & \multicolumn{2}{|l|}{ No } & \multicolumn{2}{|c|}{ Yes } \\
\hline & $N$ & $\%$ & $n$ & $\%$ \\
\hline Discussed clients in public places or with nonmedical personnel & 189 & $77.5 \%$ & 55 & $22.5 \%$ \\
\hline Reported or recorded vital signs that were not taken or recalled accurately & 213 & $87.3 \%$ & 31 & $21.7 \%$ \\
\hline Recorded client responses to treatments or medications that were not assessed & 221 & $90.6 \%$ & 23 & $9.4 \%$ \\
\hline Reported or recorded treatments that were not performed or observed & 223 & $91.4 \%$ & 21 & $8.6 \%$ \\
\hline $\begin{array}{l}\text { Attempted to perform a procedure on a client without adequate knowledge or failed } \\
\text { to obtain guidance from the instructor }\end{array}$ & 228 & $93.4 \%$ & 16 & $6.6 \%$ \\
\hline Broke sterile technique and neither reported it nor replaced contaminated items & 230 & $94.3 \%$ & 14 & $5.7 \%$ \\
\hline Not reporting an incident or error that involves a client & 231 & $94.7 \%$ & 13 & $5.3 \%$ \\
\hline Recorded medications as given when they were not given & 243 & $99.6 \%$ & 1 & $0.4 \%$ \\
\hline Lost, broke, or damaged clients' belongings and did not report it & 243 & $99.6 \%$ & 1 & $0.4 \%$ \\
\hline
\end{tabular}



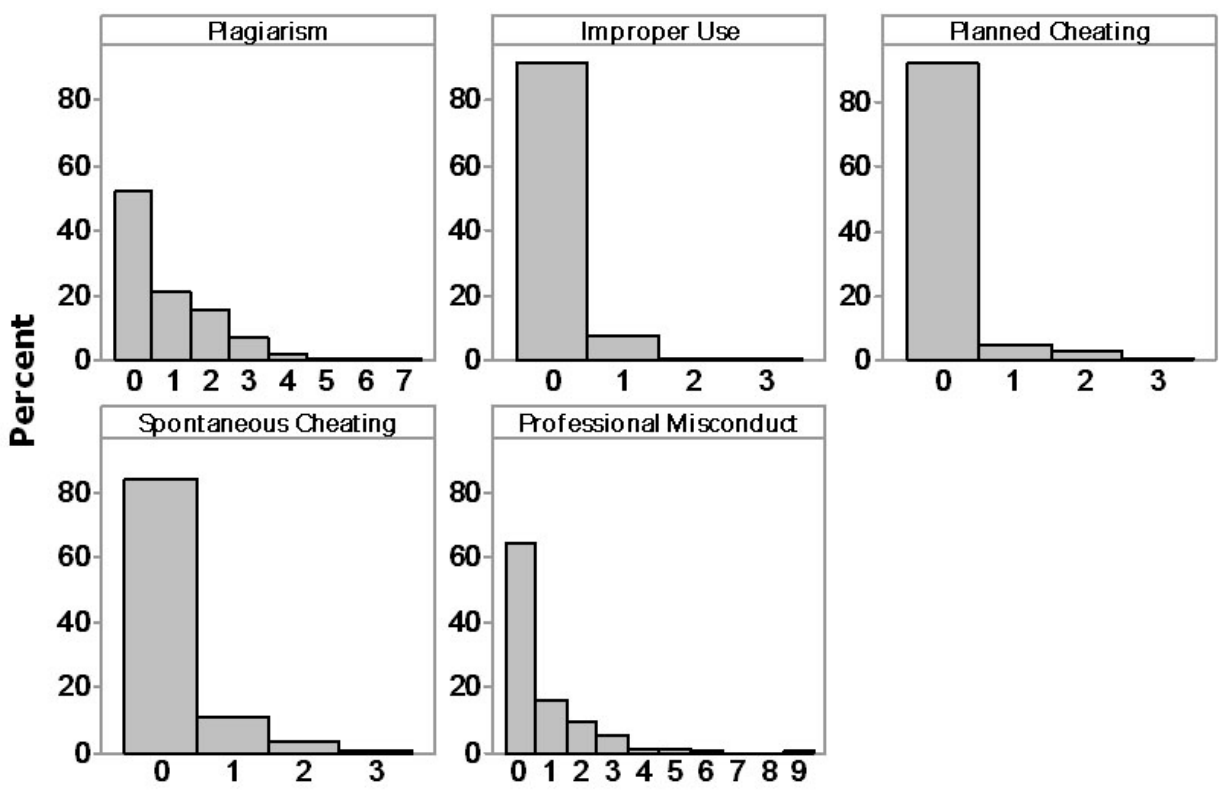

Figure 1. Frequency distributions of five categories of misconduct

Table 6. Descriptive statistics and reliability analysis for the five categories of misconduct

\begin{tabular}{lllllll}
\hline Category of Misconduct & $\boldsymbol{M}$ & $\boldsymbol{M d n}$ & Mode & $\boldsymbol{S D}$ & Skewness & Reliability coefficient \\
\hline Plagiarism & .90 & 0 & 0 & 1.21 & 1.51 & .686 \\
Improper Use & .09 & 0 & 0 & 0.33 & 4.47 & .622 \\
Planned Cheating & .14 & 0 & 0 & 0.47 & 3.92 & .598 \\
Spontaneous Cheating & .27 & 0 & 0 & 0.60 & 2.26 & .606 \\
Professional Misconduct & .72 & 0 & 0 & 1.29 & 2.62 & .701 \\
\hline
\end{tabular}

Table 7. Frequency distribution of responses to the 10 items in the social desirability scale

\begin{tabular}{|c|c|c|c|c|}
\hline \multirow{2}{*}{ Item } & \multicolumn{2}{|c|}{ Score $=0$} & \multicolumn{2}{|c|}{ Score $=1$} \\
\hline & $n$ & $\%$ & $n$ & $\%$ \\
\hline 4. I always try to practice what I preach. & 38 & $6.1 \%$ & 589 & $93.9 \%$ \\
\hline 3. I am always willing to admit it when I make a mistake. & 151 & $24.1 \%$ & 476 & $75.9 \%$ \\
\hline 8. I never resent being asked to return a favor. & 161 & $25.7 \%$ & 466 & $74.3 \%$ \\
\hline 5. I sometimes try to get even rather than forgive and forget. & 171 & $27.3 \%$ & 456 & $72.7 \%$ \\
\hline 2. There have been occasions when I took advantage of someone. & 227 & $36.2 \%$ & 400 & $63.8 \%$ \\
\hline 7. There have been occasions when I felt like smashing things. & 285 & $45.5 \%$ & 342 & $54.5 \%$ \\
\hline 9. I have never been irked when people expressed ideas very different from my own. & 380 & $60.6 \%$ & 247 & $39.4 \%$ \\
\hline 10. I have never deliberately said something that hurt someone’s feelings. & 332 & $53.0 \%$ & 295 & $37.0 \%$ \\
\hline 6. At times I have really insisted on having things my own way. & 447 & $71.3 \%$ & 180 & $28.7 \%$ \\
\hline 1. I like to gossip at times. & 469 & $74.8 \%$ & 158 & $25.2 \%$ \\
\hline
\end{tabular}

\subsection{Research questions}

3.3.1 Does the frequency of misconduct vary with respect to the demographic and academic characteristics of the students?

Because the frequency distributions of the composite scores for each category of misconduct deviated strongly from nor- mality, non-parametric statistics were applied to address this question. Spearman's rank correlation coefficients (rho) were computed to determine if correlations existed between the ordinal scores for the students' demographic and academic characteristics (age, highest level of parents' education, semester credits completed, and cumulative GPA) and 
the frequencies of the five categories of misconduct. The results are presented in Table 8.

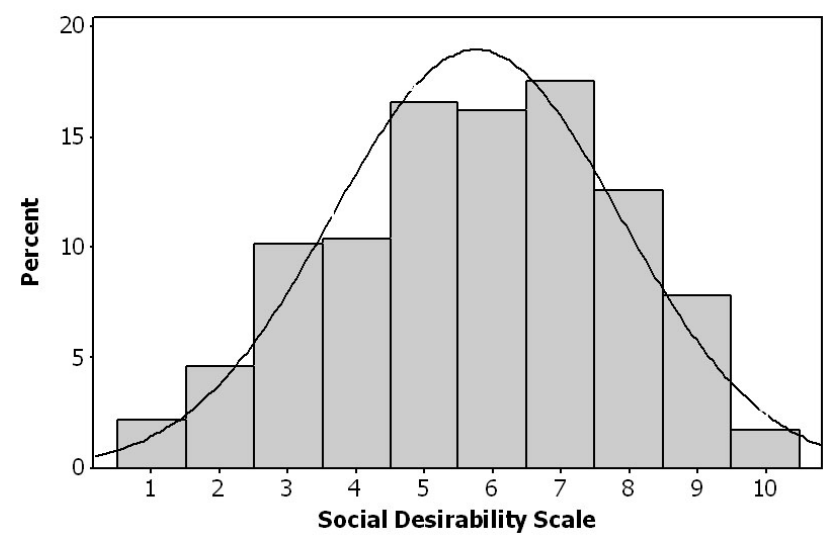

Figure 2. Frequency distribution of the social desirability scale $(\mathrm{N}=626)$

Note. High score $=$ high propensity for endorsing socially desirable behaviors

Plagiarism frequency was significantly negatively correlated with age and semester credits completed, implying that plagiarism was most frequent among the younger students with less semester credits completed; planned cheating was also significantly negatively correlated with age, an implication that younger students engaged in this misconduct most frequently. The frequency of spontaneous cheating was significantly negatively correlated with age and semester credits completed, implying that spontaneous cheating was most frequent among the younger students with fewer semester credits completed; and, finally, the regularity of professional misconduct among nursing students in terms 2,3 , and 4 was profoundly negatively correlated with age, suggesting that professional misconduct was most prevalent among the younger nursing students.

Pearson's Chi Square tests using Cramer's V coefficients to indicate the effect size were computed to determine whether associations existed between the frequencies of the nominal demographic and gender of the students and the frequencies of the five categories of misconduct. As reflected in Table 9 , the results reveal that there was not a significant difference between gender and any of the five classifications of cheating.

\subsubsection{Does social desirability bias vary with respect to the demographic and academic characteristics of the students?}

Because the frequency distributions of the composite scores for each category of misconduct deviated strongly from normality, non-parametric statistics were applied to address this question. Spearman's rank correlation coefficients (rho) were computed to determine whether correlations existed between the ordinal scores for the demographic and academic characteristics of the students (age, highest level of parents' education, semester credits completed, and cumulative GPA) and the Social Desirability Scale. The results are presented in Table 10.

Table 8. Correlation (Spearman's rho) between ordinal student characteristics and frequencies of misconduct

\begin{tabular}{llllll}
\hline Characteristic & Plagiarism & Improper use & Planned cheating & Spontaneous cheating & Professional misconduct \\
\hline $\begin{array}{l}\text { Age } \\
\text { Highest level } \\
\text { of parents' education }\end{array}$ & $-.228^{*}$ & -.063 & $-.187^{*}$ & $-.178^{*}$ & $-.176^{*}$ \\
$\begin{array}{l}\text { Semester credits } \\
\text { completed }\end{array}$ & $-.144^{*}$ & -.060 & .033 & -.046 & -.011 \\
Cumulative GPA & .077 & -.021 & .047 & $-.142^{*}$ & -.015 \\
\hline
\end{tabular}

* Significant correlation $(p<.05)$

Table 9. Associations (Cramer's V) between nominal student characteristics and frequencies of misconduct

\begin{tabular}{llllll}
\hline Student Characteristic & Plagiarism & Improper use & Planned cheating & Spontaneous cheating & Professional misconduct \\
\hline Gender & .084 & .121 & .132 & .067 & .179 \\
\hline Note. * Significant association $(p<.05)$ & & & &
\end{tabular}

The Social Desirability Scale was significantly positively correlated with age and semester credits completed, implying that social desirability bias was most frequent among the older students with more semester credits completed. The Social Desirability Scale was significantly negatively correlated

Published by Sciedu Press with the highest level of parents' education, implying that social desirability bias was less frequent among the students whose parents had a higher education level.

Kruskal-Wallis tests were conducted to indicate if the median 
scores for the Social Desirability Scale varied with respect to the nominal demographic and academic characteristics of the students (gender, campus currently attended, and program). The results are presented in Table 11.

Table 10. Correlation (Spearman's rho) between ordinal student characteristics and social desirability bias

\begin{tabular}{ll}
\hline Student characteristic & Social desirability scale \\
\hline Age & $.174^{*}$ \\
Highest level of parents' education & $-.106^{*}$ \\
Semester credits completed & $.198^{*}$ \\
Cumulative GPA & -.009 \\
\hline
\end{tabular}

* Significant correlation $(p<.05)$

Table 11. Correlation between nominal demographics and social desirability bias

\begin{tabular}{lll}
\hline Student characteristic & Kruskal-Wallis statistic & $\boldsymbol{P}$ \\
\hline Gender & 0.27 & .602 \\
Campus currently attended & 15.22 & $<.001^{*}$ \\
Program & 10.92 & .142 \\
\hline
\end{tabular}

* Significant correlation $(p<.05)$

The Social Desirability Scale varied significantly with respect to the campus currently attended. The highest median score was for the online students $(\mathrm{Mdn}=7.00)$ followed by the students at the Remote campus ( $M d n=6.28)$ while students at the Main campus possessed the lowest level of social desirability bias $(\mathrm{Mdn}=5.57)$.

\subsubsection{Does the frequency of academic misconduct in the classroom vary with respect to misconduct in the clinical setting?}

Spearman's rank correlation coefficients $(\rho)$ were computed to determine if the composite scores for the five types of academic misconduct in classroom settings were correlated with the composite scores for professional misconduct in clinical settings. The correlation matrix in Table 12 indicated that the scores for all the categories of Academic Misconduct of were significantly $(p<.05)$ positively correlated with the scores for Professional Misconduct.

\subsubsection{Does the frequency of misconduct vary with respect to familiarity with the academic code?}

Spearman's rank correlation coefficients (rho) were computed to determine if the composite scores for the five types of misconduct were correlated with the scores for familiarity with the university honor code. The correlation matrix in Table 13 indicated that there were no significant correlations between the scores $(p>.05)$.
Table 12. Correlations between academic and professional misconduct

\begin{tabular}{ll}
\hline Misconduct & Correlation with clinical misconduct \\
\hline Plagiarism & $.473^{*}$ \\
Improper Use & $.475^{*}$ \\
Planned Cheating & $.348^{*}$ \\
Spontaneous Cheating & $.362^{*}$ \\
\hline * Significant correlation $(p<.05)$
\end{tabular}

Table 13. Correlations between misconduct and familiarity with academic code

\begin{tabular}{ll}
\hline Variable & $\begin{array}{l}\text { Correlation with familiarity } \\
\text { with university honor code }\end{array}$ \\
\hline Plagiarism & .027 \\
Improper Use of Materials & .023 \\
Planned Cheating in Examinations & .037 \\
Spontaneous Cheating in & -.019 \\
Examinations & .045 \\
Clinical Misconduct &
\end{tabular}

\section{Discussion}

The current study found that $53.8 \%$ of undergraduate nursing students (pre-nursing and admitted) self-reported having engaged in acts frequently classified as academic cheating during the preceding semester. The results are slightly lower than Kruger's ${ }^{[4]}$ study (64.7\%) as well as McCabe's ${ }^{[30]}$ study, concluding that $58 \%$ of the nursing students had engaged in at least one act of academic misconduct. While previous literature has predominately focused on the overall prevalence of cheating and misconduct, the existing study provides greater insight into the frequency of cheating by categorizing cheating into five different components, comprised of (a) planned cheating on exams, (b) spontaneous cheating on exams, (c) plagiarism, (d) improper use of resources, and (e) misconduct in the clinical setting. Even as the frequency distribution reflected that $53.8 \%$ of students had engaged in at least one prohibited act during the previous semester, the majority of academic misconduct was centered on plagiarism. More specifically, the primary self-reported acts of misconduct included working together on assignments without securing permission $(34.4 \%)$ and using resources without proper attribution of credit (26.6\%).

The elevated levels of academic misconduct relating to improper collaboration and plagiarism are not surprising. In a study conducted by McCabe, ${ }^{[33]}$ less than one third of undergraduate students surveyed considered collaboration on an individual assignment to be either moderate or serious cheating. Likewise, Arhin ${ }^{[34]}$ found that only $59 \%$ of the senior baccalaureate nursing students considered certain acts 
of plagiarism as a form of academic misconduct. Thus, the higher rates of plagiarism might reflect the students' lack of understanding as to proper protocol and the behavior's seriousness. The affirmative responses to the other questions indicated relatively low levels of misconduct, ranging from a high of $13.9 \%$ to a low of $0.8 \%$. Moreover, the composite values for each of the four categories of classroom cheating were low, with a median score of zero.

In addition to exploring the overall prevalence of academic cheating, this study investigated whether the frequency of academic misconduct varies with respect to the demographic and academic characteristics of the students. The study provided mixed results as to whether students undergo a maturation process. The results from the current study indicate that there is a statistically significant relationship between the age of the respondent and prevalence of academic cheating with regard to plagiarism, planned cheating, and spontaneous cheating, implying that younger students cheat more frequently than older students in each of those three categories. The only form of academic cheating in which there was not a significant relationship with age was improper use of resources. The results are consistent with a growing body of research finding that younger students tend to cheat more than older students. ${ }^{[35-38]}$ Additionally, there was a statistically significant relationship between age and professional misconduct, indicating that younger students are more likely to engage is misconduct within the clinical setting. While there was a correlation between age and three of the four categories of academic cheating as well as clinical misconduct, number of credits hours completed was only significantly correlated with plagiarism and spontaneous cheating.

Interestingly, there was not a significant relationship between any of the four classifications of cheating or professional misconduct and the characteristics of grade point average, gender, or level of parent's education. The results relating to the education level of the parent are consistent with previous studies that found that first generation students do not cheat more frequently than students whose parents have previously attained advanced degrees. ${ }^{[38,39]}$ While results relating to the education of the level of the parent are consistent with existing literature, the findings relating to grade point average were surprising, as extant research has consistently found a relationship between grade point average and prevalence of academic cheating. The difference between the results from the current study and existing literature might be attributable to the 3.30 grade point average necessary for admission into the nursing program, thus resulting in a relatively homogenous grade point average.

The second research question explored whether social desir- ability bias varied with respect to the demographic and academic characteristics of the students. The results indicated that social desirability was significantly positively correlated with age and semester credits completed and suggested that social desirability bias was most frequent among the older students with more semester credits completed, which is inverse to the results that relate to cheating frequency. This proved interesting, as it might help account for reasons previous studies have found a maturation process, as students may become more apt to misrepresent their academic practices based upon experience and education. As such, future studies should use social desirability bias as a mediating variable when exploring the existence of a maturation process. In addition to finding a positive relationship, the current study found that social desirability bias was significantly negatively correlated with the highest level of parents' education, implying that social desirability bias was less frequent among the students whose parents had a higher level of education. In other words, first generation students were more likely to minimize their negative behaviors.

The third research question explored whether the frequency of academic misconduct in the classroom varied with respect to misconduct in the clinical setting. The results of the current study found a statistically significant relationship between cheating and engagement in misconduct. This relationship persisted with regard to each of the four types of academic cheating. The results align with the extant studies that find a positive correlation between the prevalence of academic misconduct and engagement in clinical misconduct. ${ }^{[4,11]}$ The current study, however, advances the literature by providing additional insight into whether there is a difference between the type of academic cheating and the relationship with clinical misconduct. The current study indicates that the relationship is not isolated to a specific form of academic cheating, but that if the student engages in any of the four general classifications they are more likely to engage clinical misconduct.

The final research question explored whether the frequency of academic misconduct varied with respect to familiarity with the academic code. The results of the study did not find a statistically significant correlation between familiarity of the code and any of the four classifications of academic cheating or professional misconduct. Previous research indicates that universities that implement an honor code experience significantly less academic dishonesty than universities that lack such a code. ${ }^{[40]}$ The current literature, however, indicates that mere familiarity with the code is not substantially correlated with the prevalence of academic cheating. Instead, the research might support the findings that the more integrated the honor code the lower levels of academic cheating. ${ }^{[40]}$ 


\section{Conclusion}

While extant research has explored the various academic and demographic characteristics as they pertain to the prevalence of academic cheating of nursing students and clinical misconduct using self-reported data, the existing literature is wanting in regard to nursing students' propensity to display socially desirable bias when answering questions related to cheating and clinical misconduct behaviors. The current study served to address the gap in the literature by adding the dimension of social desirability as a factor in addition to exploring the association between academic cheating and a number of academic and demographic characteristics.

The results indicate that there are statistical differences among the scores on the social desirability scale and the respondents' age, education of parent, semester credits completed, and campus attended. The results of the current study are significant, as this is the first study that involves the prevalence of cheating among nursing students and the relationship with social desirability bias. The results of this study advance the understanding of academic cheating by providing additional insight into the bias that exists in selfreported studies when surveying nursing students about their cheating behaviors.

In addition to providing insight into the interaction between academic cheating and social desirability bias, this study provides important context as to the various forms of academic cheating by using statistical analysis to segment academic cheating and misconduct into five separate components. Thus, this study provides a deeper analysis into the various academic and demographic characteristics and the student's engagement into specific acts of cheating ranging from intentional acts of cheating on exams to plagiarism. By segmenting cheating into five separate components, the results provide faculty and student services professionals with additional insight as they continue to develop new and innovative ways to safeguard against cheating. Moreover, the study also advances the literature relating to the relationship between academic cheating and professional misconduct by finding that the relationship persists with regard to each of the four forms of academic cheating.

\subsection{Implications for faculty and student services profes- sionals}

The results of the current study have significant implications for faculty members and student services professionals. As there is a correlation between academic cheating and professional misconduct, it is important to proactively implement cheating prevention efforts. To accomplish this objective, there are a couple safeguards that can thwart these behaviors.
Firstly, students need to have a clear understanding as to what types of activities constitute academic cheating and professional misconduct. Since there is not a uniform definition as to what actions constitute misconduct, students may not understand that they are engaging in a prohibited act. For example, Arhin ${ }^{[34]}$ found that $41 \%$ of the senior baccalaureate nursing students surveyed in his study did not classify acts of plagiarism as cheating. Additionally, researchers have found that in some cultures copying material in resources is a sign of respect, ${ }^{[41]}$ confounding the issue. Likewise, McCabe ${ }^{[33]}$ found that only $32 \%$ of undergraduate students in his study classified collaborating on an individual assignment as an instance on moderate or serious cheating, as compared to $82 \%$ of faculty members. Thus, it is imperative that nursing programs provide a thorough definition as to what type of conduct constitutes academic cheating, as well as improper behavior within the clinical setting.

Secondly, nursing programs should develop an honor code that conveys expectations about acceptable behaviors, including conduct within clinical settings. Research shows that universities that implement an honor code experience lower levels of self-reported cheating. ${ }^{[40]}$ As the current study reflects, however, the mere adoption of an honor code may not significantly impact the prevalence of academic cheating and professional misconduct. As a result, academic misconduct can be further moderated when implementation of the honor codes permeates into the school's culture. ${ }^{[38,42]}$ There are several ways this can be accomplished. For example, the nursing program can develop an integrity pledge as part of the admissions application process. The integrity pledge can be used to reinforce and memorialize the importance of demonstrating academic integrity. The pledge could be comprised of a simple two sentence declaration to which each nursing student must subscribe when they are accepted into the program. Likewise, the program should consider adopting an integrity oath to help reinforce the expectations of academic honesty. The declaration should address unauthorized collaboration and plagiarism as those were the two primary forms of misconduct. An example of the code is as follows: I affirm that the submitted material is my original work and that I did not collaborate with classmates without the instructor's express permission. I confirm that the assignment was not previously submitted, in whole or in part, in another class. Moreover, I did not use any unauthorized resources and have used appropriate citations that attribute credit to the proper sources.

\subsection{Employers and clinical settings}

While colleges and universities need to reinforce the importance of academic and professional conduct, future employ- 
ers and organizations providing clinical settings also have a duty to provide important instruction as it not only impacts their future personnel needs, but may also impact their legal culpability based upon the theory of respondeat superior. The prospect for legal liability is magnified as previous research has indicated that students who engage in academic cheating are more likely to engage in workplace misconduct. ${ }^{[12]}$ This is further supported by the research form the current study finding a correlation between academic cheating and misconduct in the clinical setting.

Employers and clinical site providers might be positioned uniquely to provide influence about the importance of ethical conduct as one of the reasons students cheat is to augment their grades ${ }^{[43,44]}$ to enhance their attractiveness to potential employers. ${ }^{[2]}$ Healthcare organizations can assist with the efforts of ferreting out academic cheating and professional misconduct by partnering with local nursing programs. This can be accomplished by availing representatives to serve as guest speakers to convey the importance of operating in an ethical manner as well as providing an orientation during clinical settings that specify the expectations of the student nurse, including the importance of patient privacy and accurate recordkeeping.

\subsection{Limitations}

One of the central limitations of this study is that the population consists of students from one regional university located in the Midwest that offers undergraduate and graduate degrees, including the DNP. Since the population is restricted to nursing majors at one regional university, future researchers must be careful in extrapolating the results to different disciplines or different academic institutions. Additionally, the current study used self-reported student surveys to determine the prevalence of academic cheating within the past semester. As a result, there is a risk that students were dishonest in regard to their past cheating behaviors. In order to minimize the risk, a social desirability scale was used to determine whether the data was subject to respondent error. Even with the additional safeguard, the risk of bias remains.

\subsection{Future research}

The current study found that younger students are more likely to plagiarize, engage in planned and unplanned cheating, and to participate in misconduct within the clinical setting. Likewise, students with fewer credit hours are more likely to plagiarize and partake in spontaneous cheating. Interestingly, the study also found that older students and student who have earned more credit hours displayed higher levels of social desirability bias; this tendency might help account for previous research that found the existence of a maturation process. In other words, previous studies that found that students engage in less misconduct as they age might be attributable to heightened levels of social desirability bias. While this is only one possible explanation, future research should be designed to replicate this study using a larger and more diverse population.

\section{CONFLICTS OF INTEREST Disclosure}

The authors declare that there is no conflict of interest statement.

\section{REFERENCES}

[1] Simkin MG, McLeod A. Why do college students cheat? Journal of Business Ethics. 2010; 94(3): 441-453. http://dx.doi.org/10. 1007/s10551-009-0275-x

[2] Spence M. Job market signaling. Quarterly Journal of Economics. 1973; 87(3): 355-374. http://dx.doi.org/10.2307/1882010

[3] Caruna A, Ramaseshan B, Ewing MT. The effect of anomie on academic dishonesty among university students. International Journal of Educational Management. 2000; 14(1): 22-30. http://dx.doi.o $\mathrm{rg} / 10.1108 / 09513540010310378$

[4] Krueger L. Academic dishonesty among nursing students. The Journal of Nursing Education. 2014; 53(2): 77-87. http://dx.doi.o $\mathrm{rg} / 10.3928 / 01484834-20140122-06$

[5] Zerbe WJ, Paulhus DL. Socially desirable responding in organizational behavior: A reconception. The Academy of Management Review. 1987; 12(2): 250-264.

[6] Randall DM, Gibson AM. Methodology in business ethics research: A review and critical assessment. Journal of Business Ethics. 1990; 9(6): 457-471. http://dx.doi.org/10.1007/BF00382838

Published by Sciedu Press
[7] Bernardi RA, Adamaitis KL. Data contamination by social desirability response bias: An international study of students' cheating behavior. Research on Professional Responsibility and Ethics in Accounting. 2006; 11: 157-184

[8] Whitley BE. Factors associated with cheating among college students: A review. Research in Higher Education. 1998; 39(3): 235-274. http://dx.doi.org/10.1023/A:1018724900565

[9] Jeffreys MR, Stier LA. Student academic dishonesty. Imprint. 1998; 45(3): 48. PMid:9849217

[10] Langone M. Educational innovation: Promoting integrity among nursing students. Journal of Nursing Education. 2007; 46(1): 45-47. PMid: 17302100

[11] Hilbert GA. Involvement of nursing students in unethical classroom and clinical behaviors. Journal of Professional Nursing. 1985; 1(4): 230-234. http://dx.doi.org/10.1016/S8755-7223(85 ) $80160-5$

[12] Nonis S, Swift CO. An examination of the relationship between academic dishonesty and workplace dishonesty: A multicampus investigation. Journal of Education for Business. 2009; 77(2): 69-77. http://dx.doi.org/10.1080/08832320109599052 
[13] Lin SC, Wen ML. Academic dishonesty in higher education - a nationwide study in Taiwan. Higher Education. 2007; 54(1): 85-97. http://dx.doi.org/10.1007/s10734-006-9047-z

[14] Teodorescu D, Andrei T. Faculty and peer influences on academic integrity: College cheating in Romania. Higher Education. 2009; 57(3): 267-282. http://dx.doi.org/10.1007/s10734-008-9143-3

[15] Ashworth P, Bannister P, Thorne P. Guilty in whose eyes? University students' perceptions of cheating and plagiarism in academic work and assessment. Studies in Higher Education. 1997; 22(2): 187-203. http://dx.doi.org/10.1080/03075079712331381034

[16] Franklyn-Stokes A, Newstead SE. Undergraduate cheating: Who does what and why? Studies in Higher Education. 1995; 20(2): 159172. http://dx.doi.org/10.1080/03075079512331381673

[17] Rakovski CC, Levy ES. Academic dishonesty: perceptions of business students. College Student Journal. 2007; 41(2): 466-481.

[18] Nuss EM. Academic integrity: comparing faculty and student attitudes. Improving College and University Teaching. 1984; 32(3): 140144. http://dx.doi.org/10.1080/00193089.1984.1053386 2

[19] Whitley BE, Kost CR. College students' perceptions of peers who cheat. Journal of Applied Social Psychology. 1999; 29(8): 1732 1760. http://dx.doi.org/10.1111/j.1559-1816.1999.tb0 2048. $\mathrm{x}$

[20] McCrink A. Ethical Nursing Practice. Nursing for women's health. 2010; 14(6): 443-446. PMid:21162340 http://dx.doi.org/10. $1111 / \mathrm{j} .1751-486 \mathrm{X} .2010 .01590 \cdot \mathrm{x}$

[21] Bunn DN, Caudill SB, Gropper DM. Crime in the classroom: An economic analysis of undergraduate student cheating behavior. Journal of Economic Education. 1992; 197-207. http://dx.doi .org /10.1080/00220485.1992.10844753

[22] Hard SF, Conway JM, Moran AC. Faculty and college student beliefs about the frequency of student academic misconduct. Journal of Higher Education. 2006; 77(6): 1058-1080. http://dx.doi.org /10.1353/jhe.2006.0048

[23] Grijalva T, Kerkvliet J, Nowell C. Academic honesty and online courses. College Student Journal. 2006; 40(1): 180-185.

[24] Etter S, Cramer JJ, Finn S. Origins of academic dishonesty: Ethical orientations and personality factors associated with attitudes about cheating with information technology. Journal of Research on Technology in Education. 2007; 39(2): 133-155. http://dx.doi.org /10.1080/15391523.2006.10782477

[25] McCabe DL. The Center for Academic Integrity Assessments Project Surveys. 2005. Available from: http://www .academicintegrit y.org/cai_research.asp

[26] Baum JJ. CyberEthics: The New Frontier. Techtrends: Linking Research \& Practice to Improve Learning. 2005; 49(6): 54-56. http://dx.doi.org/10.1007/BF02763731

[27] Zhang X, Hongli S, Zhang F. Preventing Plagiarism and Academic Misconduct: A Case Study of Chinese Universities, School of Foreign Languages. 2010; Available from: http://www.plagiarismadvice.com/documents/con ference2010/papers/4IPC_0020_final.pdf

[28] Gaberson KB. Academic dishonesty among nursing students. In Nursing Forum. 1997; 32(3): 14-20. http://dx.doi.org/10.1111/j .1744-6198.1997.tb00205.x

[29] Faucher D, Caves S. Academic dishonesty: Innovative cheating techniques and the detection and prevention of them. Teaching and Learn- ing in Nursing. 2009; 4(2): 37-41. http://dx.doi.org/10.1016 /j.teln.2008.09.003

[30] McCabe DL. Academic dishonesty in nursing schools: an empirical investigation. The Journal of nursing education. 2009; 48(11): 614-623. PMid:19650608 http://dx.doi.org/10.3928/01484 834-20090716-07

[31] Curran K, Middleton G, Doherty C. Cheating in exams with technology. International Journal of Cyber Ethics in Education. 2011; 1(2): 54-62. http://dx.doi.org/10.4018/ijcee. 2011040105

[32] Strahan R, Gerbasi KC. Short, homogeneous versions of the MarlowCrowne Social Desirability Scale. Journal of Clinical Psychology. 1972; 28(2): 191-193. http://dx.doi.org/10.1002/1097-467 9 (197204) $28: 2<191:$ : AID-JCLP2270280220>3 . 0 . CO ; 2-G

[33] McCabe DL. Cheating among college and university students: A North American perspective. International Journal for Educational Integrity. 2005; 1(1).

[34] Arhin AO. A pilot study of nursing student's perceptions of academic dishonesty: A generation Y perspective. ABNF Journal. 2009; 20(1): 17-21. PMid:19278183

[35] Baird JS. Current trends in college cheating. Psychology in the Schools. 1980; 17(1): 515-522. http: //dx.doi.org/10.1002/1520-6807(198010) 17:4<515: : AID-PITS2310170417>3.0.CO;2-3

[36] Cochran J, Chamlin M, Wood P, et al. Shame, embarrassment, and formal sanction threats: Extending the deterrence/rational choice model to academic dishonesty. Sociological Inquiry. 1999; 69(1): 91-105. http://dx.doi.org/10.1111/j.1475-682x.1999.t b00491.x

[37] Haines VJ, Diekhoff GM, LaBeff EE, et al. College cheating: Immaturity, lack of commitment, and the neutralizing attitude. Research in Higher Education. 1986; 25: 342-354. http://dx. doi .org/10. 1007 /BF00992130

[38] McCabe DL, Trevino LK. Individual and contextual influences on academic dishonesty. Research in Higher Education. 1996; 38: 379396. http://dx.doi.org/10.1023/A: 1024954224675

[39] Kirkvliet J. Cheating by economic students: A comparison of survey results. Journal of Economic Education. 1994; 25(2): 121-133. http://dx.doi.org/10.1080/00220485.1994.10844821

[40] McCabe DL, Trevino LK, Butterfield KD. Honor codes and other contextual influences on academic integrity: A replication and extension to modified honor code settings. Research in Higher Education. 2002; 43(3): 357-378. http://dx.doi.org/10.1023/A : 1014893102151

[41] Hayes N, Introna LD. Cultural values, plagiarism, and fairness: When plagiarism gets in the way of learning. Ethics and Behavior. 2005; 15(3): 213-231. http://dx.doi.org/10.1207/s15327019eb15 03_2

[42] Lucas GM, Friedrich J. Individual differences in workplace deviance and integrity as predictors of academic dishonesty. Ethics \& Behavior. 2005; 15(1): 15-35. http://dx.doi.org/10.1207/s15327019 eb1501_2

[43] Jones DL. Academic dishonesty: Are more students cheating?. Business Communication Quarterly. 2011; 74(2): 141-150. http: //dx.doi.org/10.1177/1080569911404059

[44] Joseph J, Berry K, Deshpande SP. Factors that impact the ethical behavior of college students. Contemporary Issues in Education Research. 2010; 3(5): 27-34. 